\title{
Computational Dosimetry Evaluation In Vertebral Models Using A Radioactive Bone Cement With Sm-153, Ho-166, Y-90
}

\author{
Carlos Julio Montaño ${ }^{1, \psi}$, Bruno Melo Mendes², Tarcísio Passos Ribeiro Campos ${ }^{1}$ \\ ${ }^{1}$ Universidade Federal de Minas Gerais - UFMG \\ Departamento de Engenharia Nuclear - Laboratório de Radiações Ionizantes, \\ Av. Antônio Carlos, 6627, Pampulha. CEP 31270-901. Belo Horizonte-MG, Brasil \\ ${ }^{2}$ Centro de Desenvolvimento da Tecnologia Nuclear - CDTN \\ Laboratorio de Dosimetria Interna, Bloco 20
}

Recibido 2 de febrero de 2019. Aceptado 29 de julio de 2019

\begin{abstract}
Background: Breast cancer is a disease that affects a large part of the Brazilian female population. Especially, those bones metastasis developed in the spinal column. This can produce potential fractures with neurological compromise or reduction of the life's quality of the patient due to chronic pain. Objective: Computational dosimetry study in vertebrae models simulating bone metastasis locating a radioactive bone cement with Sm-153, Ho-166 or Y-90 in the vertebral body. Methods: Radiological images of animal vertebrae was used to construct a model using the MCNPx code (MonteCarlo N-Particle code). Deposited doses were evaluated in the axial plane (XY) respect to implant of the radioactive bone cement into the metastasis. The nearest organ of risk (OAR) was the spinal cord and the planning target volume (PTV) was the implant itself on the vertebrae. The Samarium-153 (Sm-153), Holmium-166 (Ho-166) and Yttrium-90 (Y-90) radionuclides were considered. Results: The therapeutic deposited dose obtained in the implant plane by radioactive bone cement reaches levels above 70 Gy for specific activities close to 3 GBq· $\mathrm{mg}^{-1}$ with suitable values for the Y-90 coupled to the cement. Exposure to Ho-166 produces a dose such that cover 76,49\% and 62,77 $\%$ for two cases with metastasis respect to PTV while Y-90 covers 94,30 \% and 80,91 \% on the PTV. Conclusions: The radioactive cement implant may potentially to make an optimal tumor control and lower side effects in organs at risk.
\end{abstract}

Keywords: Computational dosimetry, MCNPx, radioactive bone cement, Vertebroplasty.

EVALUACIÓN DOSIMÉTRICA COMPUTACIONAL EN MODELOS VERTEBRALES USANDO UN CEMENTO ÓSEO RADIOACTIVO CON SM-153, Ho-166, Y-90

Resumen- Antecedentes: El Cáncer de seno es una enfermedad que afecta a gran parte de la población brasileña femenina. Especialmente, aquellas metástasis óseas desarrolladas en la columna vertebral. Esto puede producir potenciales fracturas con compromiso neurológico o reducción de la calidad de vida de la paciente debido al dolor crónico. Objetivo: Estudio de dosimetría computacional en modelos vertebrales simulando metástasis óseas, localizando un cemento óseo radioactivo con Sm-153, Ho-166 e Y-90 en el cuerpo vertebral. Métodos: Imágenes radiológicas de vértebras animales fueron usadas para construir un modelo usando

* Dirección para correspondencia: carlmont@ucm.es

DOI: https://doi.org/10.24050/19099762.n26.2019.1370 
el código MCNPx (MonteCarlo N-Particle). Las dosis depositadas fueron evaluadas en el plano axial (XY) respecto al implante del cemento óseo radioactivo dentro de la metástasis. El órgano de riesgo (OAR) más próximo fue la médula espinal y el volumen blanco de planificación (PTV) fue el mismo implante en las vértebras. Los radionuclídeos Samario-153 (Sm-153), Holmio-166 (Ho-166) e Itrio-90 (Y-90) fueron considerados. Resultados: La dosis depositada terapeútica obtenida en el plano del implante por el cemento óseo radioactivo alcanza niveles arriba de 70 Gy para actividades específicas próximas a $3 \mathrm{GBq} \cdot \mathrm{mg}^{-1}$ con valores aceptables para el Y-90 acoplado al cemento. La exposición a Ho-166 produce una dosis tal que cubre 76,49 \% y $62,77 \%$ para dos casos con metástasis respecto al PTV mientras que Y-90 cubre $94,30 \%$ y 80,91 \% en el PTV. Conclusiones: The radioactive cement implant may potentially to make an optimal tumor control and lower side effects in organs at risk. El implante de cemento radioactivo puede potencialmente hacer un control óptimo del tumor y disminuir los efectos secundarios en los órganos de riesgo.

Palabras clave-Dosimetría computacional, MCNPx, cemento óseo radioactivo, Vertebroplastia.

\section{INTRODUCTION}

$\mathrm{R}$ adiovertebroplasty has been purpose as a variant to the orthopedical clinic protocol known as Vertebroplasty. Studies done on the possible treatment have shown to be an alternative to control bone metastases with low therapeutic response to conventional radiotheraphy treatments [1]. The use of bone cements based on PMMA (Polymethylmetacrylate) and biophosphates and others orthopedical techniques play an important role in the restoration and stabilization of collapsed vertebrae in the spinal column due to the compression provided by metastases development as spinal malignancies $[2,3]$. In many cases, the aim is the palliative pain reduction $[4,5]$. Despite the fact that the Intensity-Modulated Radiosurgery (IMR) produces a significant dose sparing the organs at risk, it remains high in the oncological patient since such dose may induce myelopathies in a long term resulting in gradual neurological compromise [6-8]. The administration of systemic ${ }^{153} \mathrm{Sm}$-EDTMP (Samarium-153-ethylene diamine tetramethylene phosphonate) has produced satisfactory pain relief in a good number of patients. Although, imaging studies performed in a certain population of cancer patients showed regional and in situ recurrences, 3 up to 6 months after treatment $[9,10]$.

The NRI/UFMG - Research group of Federal University of Minas Gerais proposed and patented the radioactive cement for bone metastasis treatment [11, 12]. Hirsch et al [13] also have explored this idea, they modeled the dose, the dose rate and the BED (Biological Effective Dose) in a vertebral bone tissue due to a beta radioactive sources distribution coupled to a PMMA implant in a spherical shape of $1 \mathrm{~mm}$ radius [14]. The most important finding in this work was the evaluation of the BED for permanent sources correlated to the linear quadratic model (LQ) for a specific $\alpha / \beta$ proposed by Dale [15], in which absorbed dose was calculated by Monte
Carlo code MCNP v.5, applied to some $\beta^{-}$- emitters such as P-32, Y-90 and Ho-166.

The Monte Carlo code has been used for countless cases of computational dosimetric calculation using stochastic methods [16]. A challenged for applying MCNPx in human dosimetry is concerning to the ability of developing human voxelized models in milimetric size that hold greater anthropomorphic and anthropometric complexities [17, 18]. Such type of digital MCNPx input file is required to ensure greater reliability in the absorbed dose calculations. Other challenge is the management of the large big data reproduced in the MCNPx output file. SISCODES system was development by Trinidade B. in the Department of Nuclear Engineering from Federal University of Minas Gerais. SISCODES system has been developed to deal with the manipulation of data provided by the stochastic methods, such as MCNPx, GEANT or EGS codes. As example, dosimetric studies of seed implants in a man pelvis models simulating Prostate Brachytherapy have already been addressed in literature [19]. The MCNP-5 code (Monte Carlo N-particle V.5) and SISCODES (Computational System for Neutron and Photon Dosimetry by Stochastic Methods) results showed a significant absorbed dose reduction in the pelvic region with the use of Pd-103 source compared to I-125 prostate implants [19]. Therefore, computational resources become an optimal alternative for estimating absorbed dose and other radiometric parameters that are often calculated using empirical dosimetric techniques.

In 2013, Blanda et al performed neutron activation of bone cement samples based on PMMA and bioceramics in a TRIGA MARK I IPR-R1 research reactor. The characterization of the samples allowed obtaining activities per milligram $\mathrm{MBq} \cdot \mathrm{mg}^{-1}$. The analysis of the contaminants in the calcium biophosphates was performed in the macroaggregate. The results showed the dosimetric viability to couple the Sm-153 and Ho-166 despite the activation of other constituent elements in the compound 
[20]. Using the LQ model and Monte Carlo MCNP v.5 and SISCODES codes, it was possible to determine dose, dose rate and BED (Biological Effectiveness Dose) for permanent implants in a lumbar tomographic vertebral model [20]. In this computational study, the bone implant were composed of PMMA+HAp holding the $\beta$-decay source of Ho-166. The Hydroxyapatite (HAp) was incorporated as bioceramic into compound. The findings showed a significant dose reduction in the organs at risk, especially in the spinal cord. A therapeutic control dose was equivalent to those achieved in conformal radiotherapy and in the IMRT $[20,21]$. The activities used in the simulation were the same as those obtained in the neutron activation in the research reactor of $32.5 \mathrm{MBq} /$ $\mathrm{mg}$ for Ho-166 source. Although, the suitable results, the radionuclide was introduced homogeneously in the vertebrae body, without considering the porosity and the non-homogeneous spatial distribution. Therefore, such attempt ion was non-realistic.

In this study, the absorbed dose calculated by using computational voxelized vertebral model and Monte Carlo code MCNP v.6 and MCNPx 2.7 [16, 17]. The spatial dose distributions were computed using three distinct radioactive sources ${ }^{153} \mathrm{Sm},{ }^{166} \mathrm{Ho}$ and ${ }^{90} \mathrm{Y}$ radioactive sources that hold therapeutic potential in performing Radiovertebroplasty.

\section{Materials And Methods}

\subsection{The radioactive bone cement synthesis}

HAp Synthesis. The HAp was synthesized by the solgel method according to Donanzan et al and Legeros et al $[12,20,22]$. The reagents used for the HAp synthesis were $3.937 \mathrm{~g}$ of calcium nitrate ${ }^{1}\left(\mathrm{Ca}\left(\mathrm{NO}_{3}\right)_{2} \cdot 4 \mathrm{H}_{2} \mathrm{O}\right), 0.69 \mathrm{~mL}$ of phosphoric $\operatorname{acid}^{2}\left(\mathrm{H}_{3} \mathrm{PO}_{4}\right), 1$ up to $2 \mathrm{~mL}$ of methanol ${ }^{3}$ $\mathrm{CH}_{3}(\mathrm{OH})$ as a catalyst for starting reaction and deionized water as solvent in excess. After mixing the components, the solution was rested for $24 \mathrm{~h}$ in a closed beaker. Precipitation, nucleation and formation of colloids had occurred. Subsequently the sample was heated in an oven. The temperature started at room temperature and ramp to $80{ }^{\circ} \mathrm{C}$ at a rate of $0.306{ }^{\circ} \mathrm{C} \cdot \mathrm{min}^{-1}$, holding $360 \mathrm{~min}$ at the $80{ }^{\circ} \mathrm{C}$ isotherm, subsequently ramp to $100{ }^{\circ} \mathrm{C}$ at the rate of $0.333{ }^{\circ} \mathrm{C} \cdot \mathrm{min}^{-1}$ holding $720 \mathrm{~min}$ at $100{ }^{\circ} \mathrm{C}$ isotherm. At the calcinations, the sample was heated from room

1. Calcium Nitrate, $\mathrm{Ca}\left(\mathrm{NO}_{3}\right)_{2} \cdot 4 \mathrm{H}_{2} \mathrm{O} 99-103 \%$ Synth. Labsynth produtos para laborátorios ltda.

2. Phosphoric acid, $\mathrm{H}_{3} \mathrm{PO}_{4} 85 \%$ P.A.-A.C.S Synth. Labsynth produtos para laborátorios ltda.

3. Methanol $\mathrm{CH}_{3}(\mathrm{OH}) 99.5 \%$ Merck. temperature to $720{ }^{\circ} \mathrm{C}$ at a rate of $6{ }^{\circ} \mathrm{C} \cdot \mathrm{min}^{-1}$, following by a $60 \mathrm{~min}$ at $720^{\circ} \mathrm{C}$ isotherm. After cooling, the HAp samples were macerated to powder.

PMMA+HAp composite preparation. HAp powder was mixed in different proportions to $\mathrm{PMMA}^{4}$ as material in powder. The composite was prepared in cold based (non-radioactive) mixing PMMA $\left(\left[\mathrm{CH}_{2} \mathrm{C}\left(\mathrm{CH}_{3}\right)\right.\right.$ $\left.\left.\left(\mathrm{CO}_{2} \mathrm{CH}_{3}\right)\right]_{n}\right)$, HAp $\left[\mathrm{Ca}_{5}\left(\mathrm{PO}_{4}\right)_{3}(\mathrm{OH})\right]$. Both PMMA and the instruments were cooled previously. The mixture was stirring. PMMA-HAp system was prepared with PMMA's micro-spheres copolymer mixed to the monomer Methyl Ethyl Methacrylate (MMA). The samples were prepared in accordance with the following concentrations $\left[x_{n}\right.$, with $\left.n=1,2\right]$, such that $x_{1}=0.0, x_{2}=0.5$. The $x_{n}$ is a value corresponding to $\mathrm{x}$ in the following system (1-x) $\left[\mathrm{CH}_{2} \mathrm{C}\left(\mathrm{CH}_{3}\right)\left(\mathrm{CO}_{2} \mathrm{CH}_{3}\right)\right]_{n}-\mathrm{x}\left[\mathrm{Ca}_{5}\left(\mathrm{PO}_{4}\right)_{3}(\mathrm{OH})\right]$ or $(1-\mathrm{x})$ PMMA-xHAp. In the case of radioactive bone cement the proportions were given as (1-x)PMMA-xHAp+y $y^{A} \mathrm{M} \cdot \mathrm{HAp}$, where $\mathrm{M}$ is the coupled radionuclide.

\subsection{Radiological Analysis}

In vitro anatomical sample preparation. The separation of a section of a pig vertebral column, in a special cut provided by a meat market, was performed in vitro embed in an equivalent muscle tissue, maintaining anatomically its structure without considering distinct anthropometric characteristics of the model. The structure was immediately cooled to $-18 \mathrm{C}$ to reduce the effect of decomposition.

Cement injection. The cement was injected into vertebral models designed in the laboratory drilling the vertebral body with a bent $45^{\circ}$ to the midsagittal plane simulating drilling needle Vertebroplasty kit.

Radiography test. The X-ray machine used was the BR 100 , a mobile system with performance $100 \mathrm{~mA}$ and 90 $\mathrm{kV}$. The BR 100 is composed with an X-ray tube sealed and linked to a telescope that is connected to the apparatus column than have an arm, which allows depending on the movement necessary adjustment of the distance between tube and film that is studied radiographically. It also has a command table with the control elements necessary for desired voltage and intensity.

According to the radiological techniques, exposure time of $0.50 \mathrm{~s}$, current of $70 \mathrm{~mA}$, voltage of $60 \mathrm{kV}$ and DFF of $85 \mathrm{~cm}$ were applied in thoracic vertebrae. Two of the radiography images are shown in Fig 1 with bone implants studied.

4. Copolymer Methyl Ethyl Methacrylate, JET self-polymerizing acrylic, Ind. Bras. CNPJ 60.858.552/0002-48.

5. Monomer Methyl Ethyl Methacrylate, JET self-polymerizing acrylic, Ind. Bras. CNPJ 60.858.552/0002-48. 


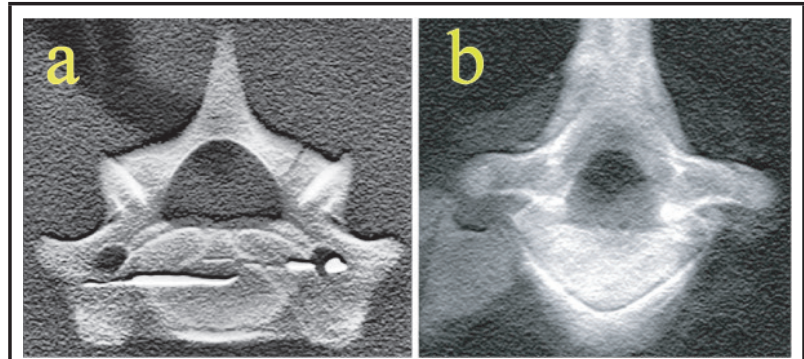

Fig.1. Radiological images selected from some vertebral models with implants.

\subsection{Computational vertebrae models}

Images treatment. The images digitized in .jpg file format were smoothed and simplified in 5 different tissues ID (Identifier) of interest, such as: 1) bone tissue with red bone marrow, 2) soft tissue, 3) medullar duct and spinal cord, 4) metastasis bone of mammary origin and $5)$ bone implant. The ImageJ software was used [23, 24]. The anatomical dimensions of the human vertebrae were conserved assuming a vertebral section of $10.50 \times 8.80 \times$ $2.3 \mathrm{~cm}^{3}$. The space outside the vertebra was considered as soft tissue. The size of the voxel was adjusted to the pixel dimensions of the image. The voxel dimensions were 0.25 x $0.25 \times 0.25 \mathrm{~mm}^{3}$.

Five universes corresponding to the aforementioned tissues were considered in the context of the MCNP v.6 and MCNPx 2.7 code [16, 17]. Two different IDs were defined with the purpose of introducing pores in the vertebral model. Those pores developed greater complexity to the universe corresponding to bone tissue.
Each voxel in the bone held a pore of spherical symmetry completely filled with red bone marrow and the excess defined as bone tissue. This novelty in the computational model improved the density of the bone tissue respect to others models without pores. Another important model characteristic was the ability to simulate a breast metastasis into the vertebral body studying its dosimetry due to expositing $\beta$-decay permanent source.

The implant of the radioactive bone cement was distributed according to the radiological image where empirically $1.20 \mathrm{~g}$ of the bone cement was introduced. In a second modeling, the amount of implant was increased to $6.77 \mathrm{~g}$. A greater cavity was simulated for the insertion of the bone implant material. The dose was evaluated in the plane of the bone implant, that is, at $\mathrm{z}=0$, exactly where the cement was inserted. In summary, Fig. 2 shows the XY-plane sections depicting the vertebral 3D models. The nomenclature VertA was adopted for the first model and $\operatorname{Vert} B$ for the second model. Both models were constructed with an array of 95 planes in the $\mathrm{Z}$ direction. Figs 2(a), 2(b) and 2(c) show the characteristic planes of the VertA. and 2(d), 2(e), 2(f) and 2(g) show the planes of $\operatorname{Vert} B$ vertebral model.

CT vertebral lumbar model. A tomographic model of a lumbar section with an array $10.80 \times 9.24 \times 8.76 \mathrm{~cm}^{3}$ and composed of 45 planes in $\mathrm{Z}$ direction was prepared. The voxel size was defined as $1.2 \times 1.2 \times 1.2 \mathrm{~mm}^{3}$. This model was designed without bone metastasis. The advantage was a greater coverage of the region with risk organs close to the bone implant region. The amount of bone implant was 7.52 $\mathrm{g}$ for every source studied in this lumbar vertebral model.

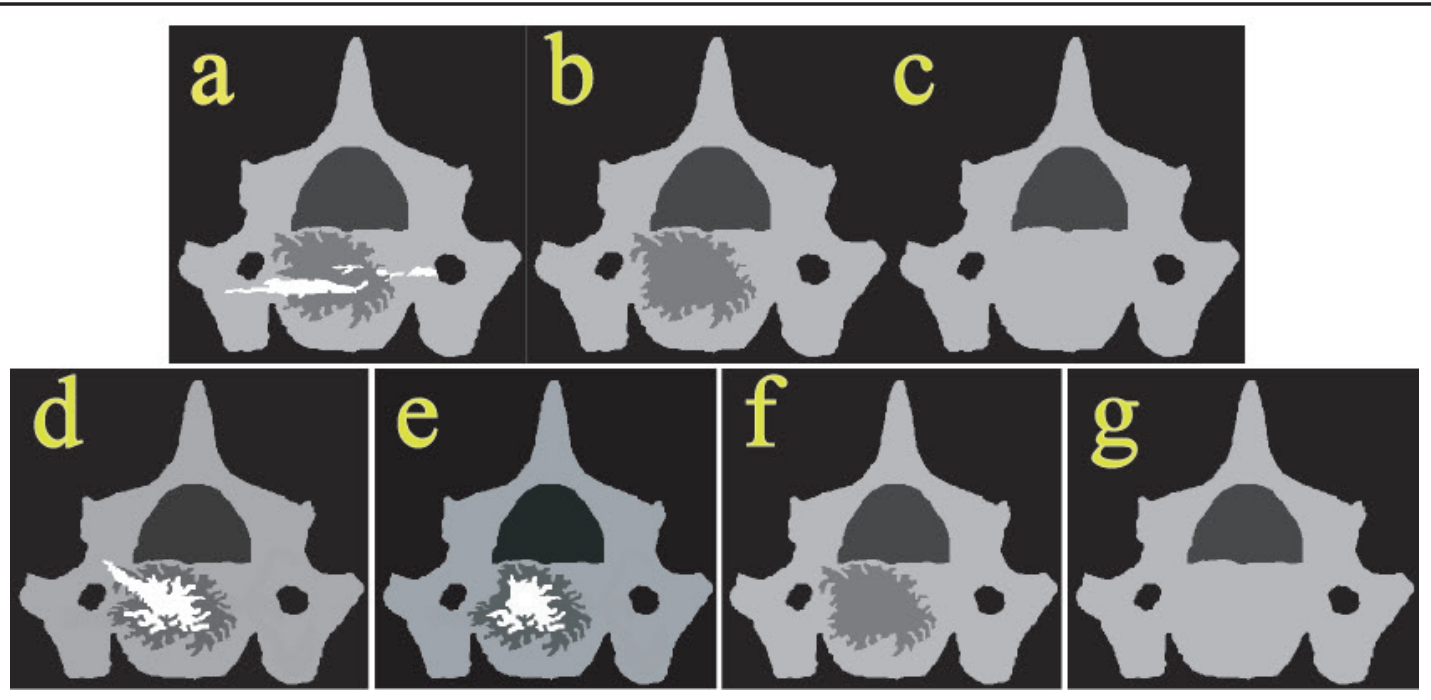

Fig. 2. XY-planes characteristics of the vertebral models with mammary metastasis. (a) Bone Implant XY-planes for VertA between $\mathrm{z}=-7$ and $\mathrm{z}$ =7. (b) Bone Metastasis XY-planes only for VertA for $(-43<\mathrm{z}<-8)$ and $(8<\mathrm{z}<43)$. (c) Bone tissue only for VertA $(-47<\mathrm{z}<-44)$ and $(44<\mathrm{z}$ $<47$ ). (d) Bone Implant XY-planes for Vert. $B$ between $\mathrm{z}=-7$ and $\mathrm{z}=7$. (e) Bone Implant XY-planes for VertB $(-31<\mathrm{z}<-8)$ and $(8<\mathrm{z}<31)$. (f) Bone Metastasis XY-planes only for VertB for $(-39<\mathrm{z}<-32)$ and $(32<\mathrm{z}<39)$. (g) Bone tissue only for Vert. $A(-47<\mathrm{z}<-40)$ and $(40<\mathrm{z}<47)$. 


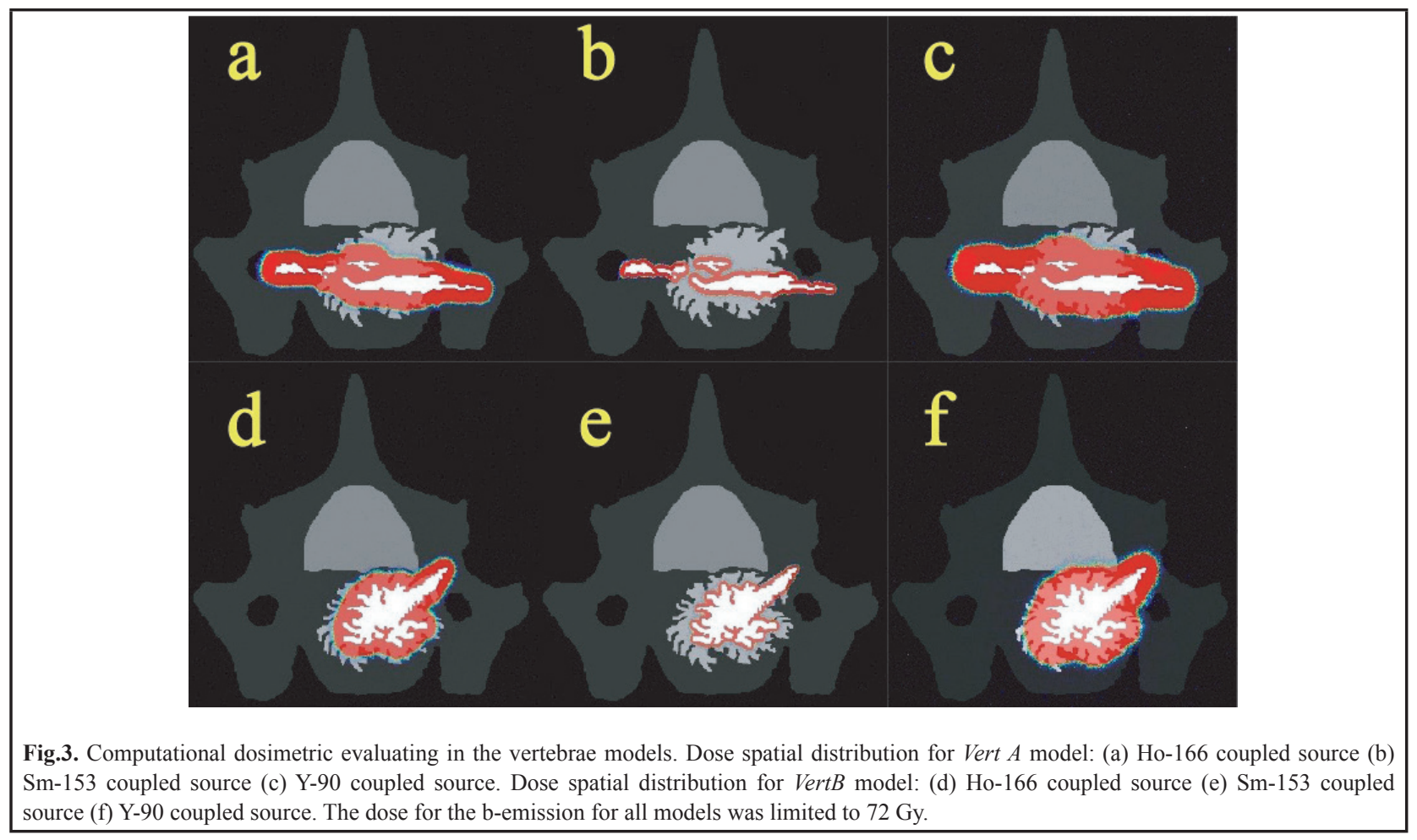

Specific activity required. The specific activity for 1 mg of the sources activated by Donanzam [20] was used here too. The estimation of the deposited dose in all voxel models without vertebral bone metastasis was calculated. The energy spectrum of the beta emissions for each radionuclide was extracted from the computer tool provided by the Nuclear Regulatory Commission of the United States (NRC US) or freely by the National Laboratory OAK RIDGE (ORNL) through the Radiological software Toolbox (Rad Toolbox v. 3.0.0 5/1/2014).

\section{REsUlts}

The MCNP6 tally card *F8 was set in the input file. This card tally provides the mean total energy deposited in a requested region of the voxelized model. The statistical treatment allowed reducing the total variance. The output file provided the total energy deposited by voxel in units of MeV. In addition, the mass and density of each voxel were presented.

The Radiological software Toolbox has a database of the radionuclides decay spectra provided by the reports of International Commission on Radiological Protection (ICRP). The beta-particle decay factor for each particle and radionuclide was expressed in particles/decay [Bq], the specific activity expressed in $[\mathrm{Bq} / \mathrm{g}]$ and the mass from voxel in grams $[\mathrm{g}]$. The absorbed dose was estimated as total decay from the source. The specific activity was chosen in the order of $3 \mathrm{GBq}$ to reach the range of 70-72 Gy and thus, the maximum levels of tolerance to the nearest risk of organ (Spinal cord) were maintained. Emami et al. suggested that for TD 50/5 (Tolerance Dose, the probability of $50 \%$ complication within five years) shall be up to 73 Gy for the spinal cord [6].

The voxel model of VertA simulated a bone implant with a mass of $1.20 \mathrm{~g}$, mimicking the radiological experiment as, shown in Fig 3. Fig 3(c) shows the images of the VertA model filled with BC-Y ${ }^{90}$ (Bone Cement- $Y^{90}$ ) and it shows a large spatial dose distribution, although it does not cover $100 \%$ of the metastasis' region. Qualitatively, in Fig 3(a), $\mathrm{BC}-\mathrm{Ho}^{166}$ shows a better performance in the spatial dose distribution if compared to $\mathrm{BC}-\mathrm{Sm}^{153}$, as has been seen in Fig 3(b). Based on the simulations, it worth to mention that the amount of cement implanted in VertA produces undesirable therapeutic effect with respect to the dose deposition since, it held a poor spatial distribution. The VertB simulated a bone implant with mass of $6.77 \mathrm{~g}$, being a greater implant amount comparing to VertA model. In this case, the implant was almost 6 times greater than the bone implant used on the VertA. In Fig 3(f) shows the images when $\mathrm{BC}-\mathrm{Y}^{90}$, is using and a large spatial distribution was achieved, despite the fact that the medullar duct had a higher dose near to the tolerance limit. In this case, the dose deposited by the implant covers almost $100 \%$ of the metastasis volume. In Fig 3(d) shows the model with the 
$\mathrm{BC}-\mathrm{Ho}^{166}$. The results showed a spatial dose distribution held the lower cover of the PTV; although, qualitatively it is possible to affirm that the source has an acceptable therapeutic behavior. In none of the cases, the use of BC$\mathrm{Sm}^{153}$ in situ reaches the full coverage with a therapeutic dose that guarantees the tumor control of the metastasis. The reference dose $\left(D_{\text {ref }}\right)$ was 72 Gy.

Also, a lumbar tomographic model was used in this case, the implant was placed in the central space of the vertebral body. The bone cement used in these experiments were $0.9 \mathrm{PMMA}+0.1 \mathrm{BaSO}_{4}$ coupled with the radioactive sources. The amount of implanted material was $7,52 \mathrm{~g}$. The absorbed dose from the chosen sources was evaluated. The transverse, coronal and sagittal planes are presented in Figs 4(a), 4(b), 4(c), respectively, with their center at the origin. The $\mathrm{BC}-\mathrm{Ho}^{166}$ source partially covered the volume of the vertebral body and in a lesser extension, the source deposited the reference dose in the medullar duct. In Figs 4(d), 4(e), 4(f), the images are shown with the $\mathrm{BC}-\mathrm{Sm}^{153}$ almost completely deposited the reference dose in the implant. The probability of deposition of the maximum tolerance dose TD 50/5 of 72 Gy was too small in the spinal cord.

Figs 4(g), 4(h), 4(i), the $\mathrm{BC}-{ }^{90} \mathrm{Y}$ distributed in a large volume of the spinal cord, increasing the risk with respect to the TD $50 / 5=72 \mathrm{~Gy}$. Treatment with this source seems more conservative. Thus, it holds a possibility of finding a better therapeutic response to metastasis control.

The dose-volume histograms are presented in Fig 5. The volume affected by $D_{\text {ref }}$ used in each organ can be compared. For both the risk organs (OAR) and for the planning target volume (PTV), the $D_{\text {ref }}$ was set based on the maximum radiotoxicity that the spinal cord and bone tissues can receive. From the radiotherapeutic point of view, regardless of the radionuclide used, this may be acceptable for PTV if at least $90 \% D_{r e f}$ is reached.
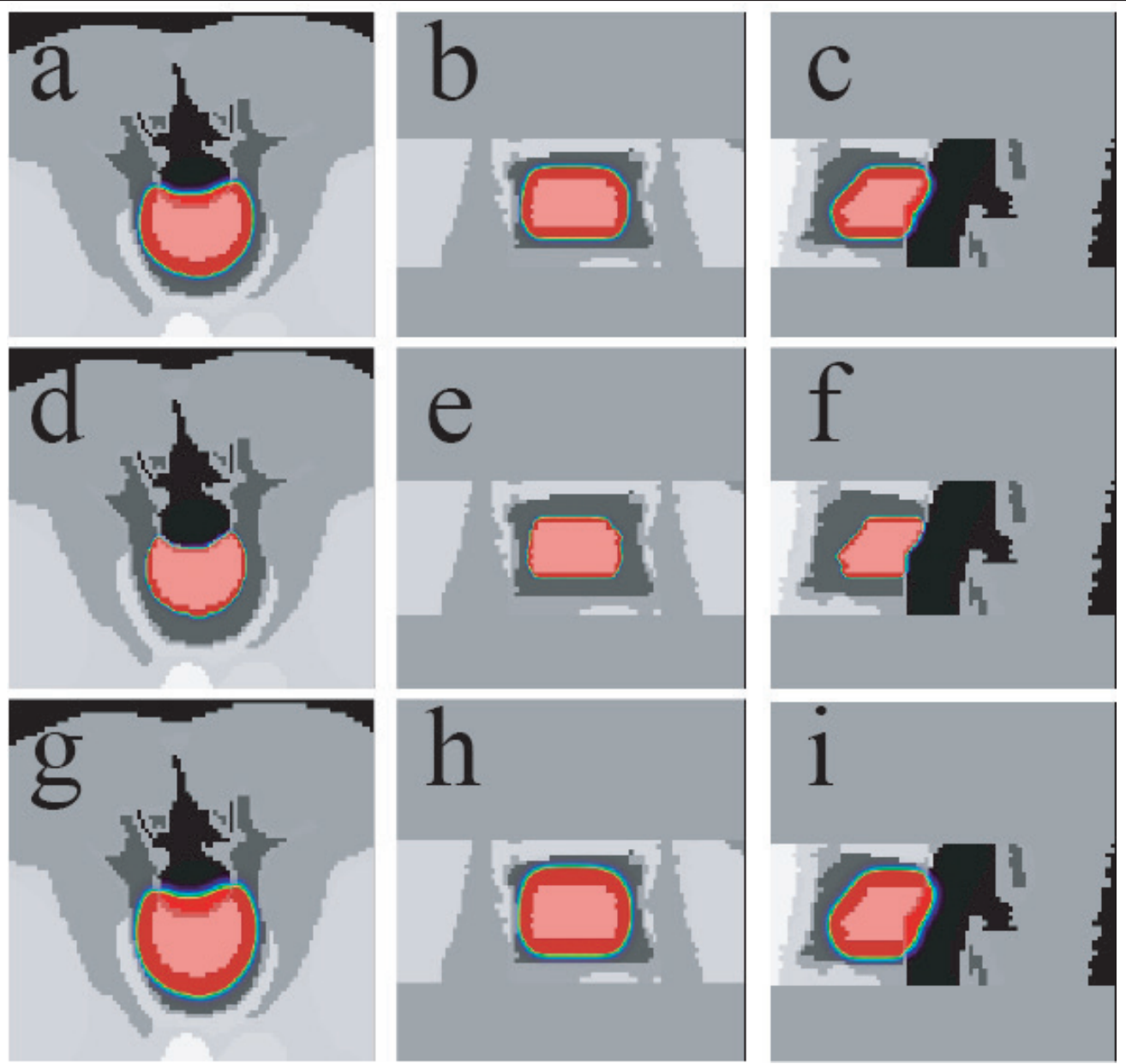

Fig.4. Dose spatial distribution for lumbar vertebral model. Ho-166 coupled source: (a) Transverse XY-plane (b) Coronal XZ-plane (d) Sagittal YZ-plane. Sm-153 coupled source: (a) Transverse XY-plane (b) Coronal XZ-plane (d) Sagittal YZ-plane. Y-90 coupled source: (a) Transverse XY-plane (b) Coronal XZ-plane (d) Sagittal YZ-plane. 

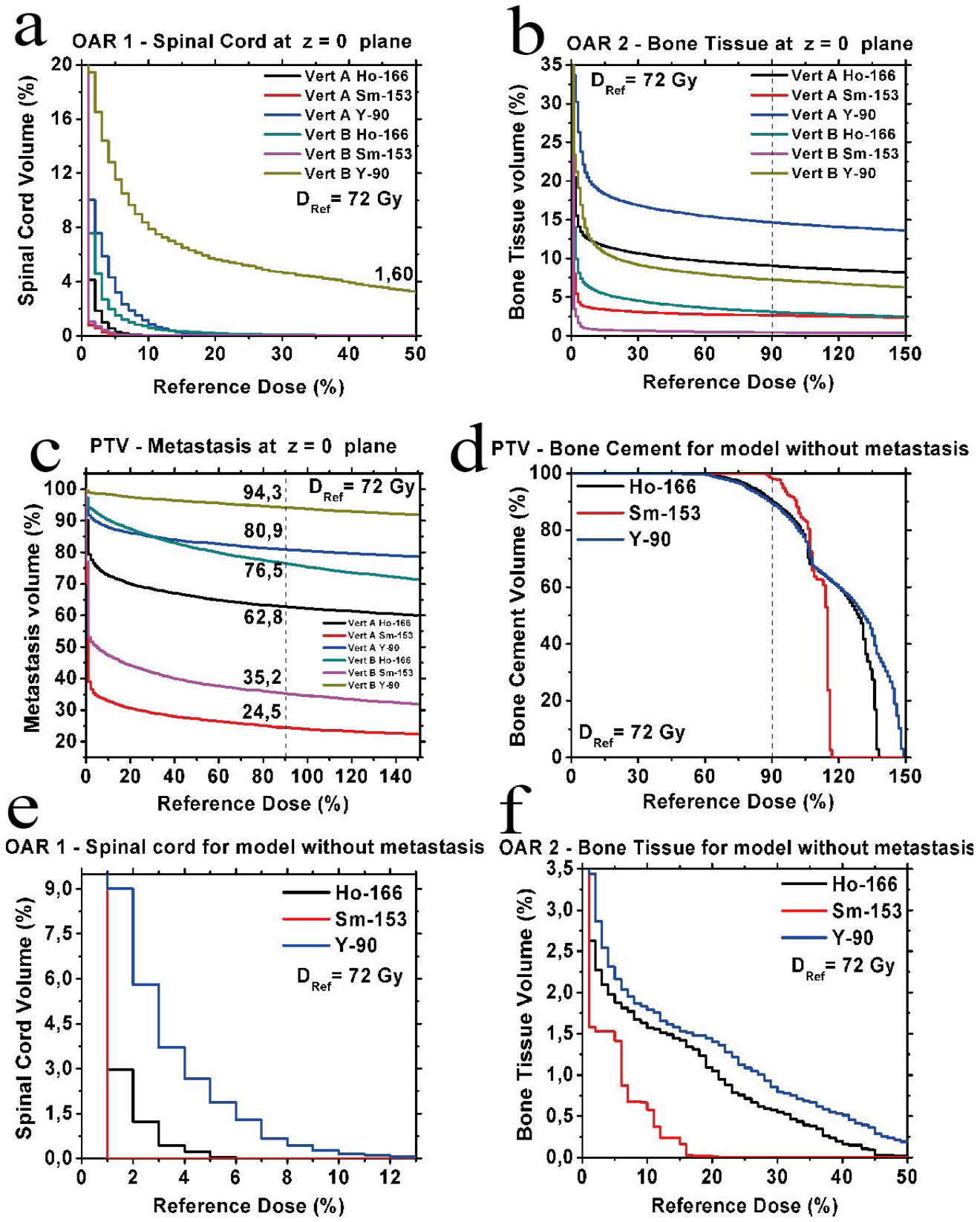

Fig. 5. Dose-Volume Histograms for PTV and OAR in vertebral models with $90 \% D_{\text {ref }}=72$ Gy. (a) OAR 1 for spinal cord at $\mathrm{z}=0$ in Vert. $A$ and Vert. $B$ (b) OAR 2 for bone tissue at $\mathrm{z}=0$ in Vert. $A$ and Vert. $B$ (c) PTV for metastasis at $\mathrm{z}=0$ in Vert. $A$ and Vert. $B$ (d) PTV for bone cement in model without metastasis (e) OAR 1 for spinal cord in model without metastasis (f) OAR 2 for bone tissue in model without metastasis.

The dose of 65 Gy meets the previous condition and according to Emami et al [6], TD 50/5 is 65 Gy as a reference value for the bone. Fig $5(\mathrm{a})$, only the $\mathrm{BC}-{ }^{90} \mathrm{Y}$ implant deposited a higher dose into the spinal cord in VertB model. The maximum committed volume that received the $72 \mathrm{~Gy}$ is less than $1.60 \%$ of the total volume of the spinal cord (OAR1). Therefore, the toxic dose only achieves the region of the dura mater into the spinal cord, thus reducing the probability of developing myelitis. In the case of the bone tissues that constitute the VertA and VertB models (OAR2), the toxic dose was a little higher because the proximity of the implant as seen in Fig. 5(b). Similarly, the committed volume for $90 \% D_{\text {ref }}$ was less than $15 \%$ of the total volume of bone tissues that constitute the vertebrae. The $\mathrm{BC}-{ }^{90} \mathrm{Y}$ was the implant that has a larger accumulative dose in the VertA model. For the vertebral model without metastasis depicting in Fig 5(e) and 5(f) The ${ }^{\mathrm{BC}}{ }^{90} \mathrm{Y}$ remains the radionuclide with the highest 
dose deposited in OAR1 and OAR2. This is important to keep in mind since the amount of bone implant used in this computational experiment corresponds to $7.52 \mathrm{~g}$. The absorbed doses were less than $90 \%$ of the $D_{\text {ref }}$ in these simulations. Therefore, the volume committed for these radiotoxic doses is negligible, being less than $0.1 \%$. Fig. 5(c), the PTV represents the vertebral metastasis for VertA and VertB models. The tally for dose was calculated on the XY-plane of the implant, with $\mathrm{BC}-{ }^{90} \mathrm{Y}$ radionuclide. Such radionuclide held a better therapeutic effect in the Vert. $B$ model since a greater spatial dose distribution was obtained, reaching up to $94.3 \%$ of the total metastasis volume for $90 \% D_{\text {ref }}$. The PTV of Fig. 5d corresponds to the implant in the model without metastasis. The specific activity was calculated in such a way that $90 \% D_{\text {ref }}$ could be obtained with respect to $90 \%$ or more of the volume with that RB cement amount.

Table 1 shows the specific activities required for each $\beta$-emitter source to satisfy with the condition that $90 \%$ of volume and $90 \%$ of $D_{\text {ref }}$ in the model without metastasis were reached. The $\mathrm{BC}-{ }^{90} \mathrm{Y}$ was the implant that requires less specific activity to reach the desired therapeutic dose levels. The $90 \% D_{r e f}$ was not reached in all cases for the OAR defined in the Table 1. A percentage ratio of volume that reaches a $D_{\text {ref }}$ percentage is presented in the Table I. Although ${ }^{90} \mathrm{Y}$ provided a higher dose levels in the spatial dose distribution, these remained a tolerable alternative to radiotoxicity due to the use of these radioactive sources.

Fig. 6 shows the volume proportion on the metastasis that reached the therapeutic dose planned as an accumulative function in the time on the VertB. It is easy to notice that ${ }^{90} \mathrm{Y}$ had a better kinetic performance compared to ${ }^{166} \mathrm{Ho}$. Despite the aforementioned, the Ho-166 could be configured as another alternative to the minimally invasive procedures in situ, performed by the Radiovertebroplasty. In both cases, after 2 days, almost full therapeutic dose was achieved. The exponential fit on the graph allows predicting what would be the percentage of volume reached after the full source decay.

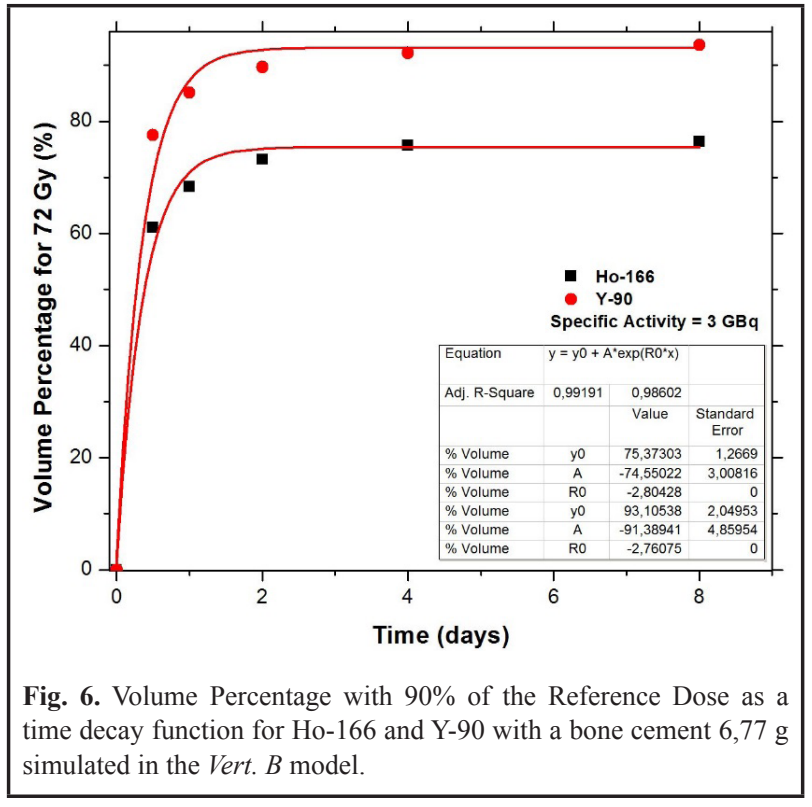

\section{Discussion}

One of the major uncertainty in radioactive implants is directly related to the dose in the vertebrae since, such value have to be planned with high dosimetric precision in terms of spatial dose distribution; while the anatomic and morphologic conditions of the vertebra body is unknown.

The guide image procedure by means of fluoroscopy is often used for the location of the bone cement during the implantation in the vertebroplasty. Therefore, a higher concentration of calcium atoms raises the attenuation factor of the cement. In our radiological experiments, the insertion of the bone cement was difficult to perform since the vertebral piece was at atmospheric pressure and bone cement held high viscosity. In the clinical situation, the vertebrae are under compression in their usual anatomical environment; this physical characteristic has been explored in Vertebroplasty to perform the procedure.

Table I. Therapeutic Dose Deposited and Radiotoxicity for PTV and OAR - Volume percentage estimated for $90 \%$ of the Reference Dose (72 Gy) concerning to TD 50/5 for each organ.

\begin{tabular}{|c|c|c|c|c|c|c|c|c|c|}
\hline \multirow{3}{*}{$\begin{array}{c}\text { Tumor, Organs or Bone } \\
\text { Cement }\end{array}$} & \multicolumn{3}{|c|}{ VertA } & \multicolumn{3}{|c|}{ VertB } & \multirow{2}{*}{\multicolumn{3}{|c|}{ Model without metastasis }} \\
\hline & \multicolumn{6}{|c|}{ Specific Activity } & & & \\
\hline & Нo-166 & Sm-153 & Y-90 & Нo-166 & Sm-153 & Y-90 & Но-166 & Sm-153 & Y-90 \\
\hline Metastasis - PTV & 62,77 & 24,47 & 80,91 & 76,49 & 35,22 & 94,30 & - - - - - & - . - - - & $\ldots \ldots$ \\
\hline Spinal Cord - OAR $1 *$ & $0.02 / 10$ & $0.01 / 7$ & $0.01 / 30$ & $0.01 / 39$ & $0.01 / 9$ & $1.80 / 90$ & $0.029 / 5$ & 0,000 & $0.058 / 12$ \\
\hline Bone Tissue - OAR $2 *$ & $9.04 / 90$ & $2.62 / 90$ & $14.65 / 90$ & $3.09 / 90$ & $0.41 / 90$ & $7.26 / 90$ & $0.007 / 55$ & $0,007 / 20$ & $0.007 / 68$ \\
\hline Bone Cement - PTV & - . - - & $-\ldots$ & $-\ldots$ & $\ldots$ & $\ldots$ & $-\ldots$ & 90.05 & 98.09 & 89.25 \\
\hline
\end{tabular}

366* \%Volume/\%Dose $\left[D_{\text {ref }}\right]$ 
The radiological images facilitated to assemble a computational model that would to be used as an input file for the dosimetric study. Later, it was on the scope to investigate the therapeutic and radiotoxic response. The computational cost of the stochastic methods becomes extremely high because the chosen small size of the voxels. Such modeling depends on the computational resources in order to carry out the simulations in days, weeks or even months. In our simulations, only absorbed doses from $\beta$-emissions were evaluated since the $\beta$-decay in the three radionuclides have the high percentage of the total energy in the emissions. In all simulations, it was confirmed that the spatial dose for the ${ }^{90} \mathrm{Y}$ was distributed in a greater area compared to ${ }^{166} \mathrm{Ho}$ and ${ }^{153} \mathrm{Sm}$. For therapeutic purposes, Sm-153 may be unsuitable use for the in situ implant. According to Fig 5(b), a smaller amount of implant mass is not directly related to the reduced dose distribution in the organs at risk (OAR) i.e. there is no directly proportional relationship, since it depends on the spatial distribution of the implant in the vertebral body. On the other hand, the implant itself acts as an attenuation element.

The logistic procedure of Radiovertebroplasty may to facilitate the patient management. It could be done without taking into account several sections of the treatment. Radiovertebroplasty may be performed in an ambulatory since it matches with conditions of a minimal invasive procedure.

\section{Conclusion}

Both $\mathrm{BC}-{ }^{90} \mathrm{Y}$ and $\mathrm{BC}-{ }^{166} \mathrm{Ho}$ are quite promising for their protocol implementation in the Radiovertebroplasty. According to the results found, the ${ }^{153} \mathrm{Sm}$ source could be more promising and in small bone sites or for vascular applications as Radioangioplasty [25]. The sources with the highest dosimetric performance deposited $90 \%$ of the dose within 2 days after to be implanted, being equivalent to Intensity-Modulated Radiosurgery or IMRT therapy with hypofractioning [26, 27].

\section{ACKNOWLEDGEMENTS}

The authors are grateful for the financial support from the CAPES, REBRAT-SUS project supported by CNPq as well as the technical assistance provided by Centro de Desenvolvimento da Tecnologia Nuclear - CDTN. The corresponding author thanks the OEA-GCUB 2014 program for the opportunity offered with the doctoral scholarship in this academic and research experience.

\section{REFERENCES}

[1]. Montaño, C.J. \& Campos, T.P.R.d. Radioactive cement of PMMA and HAP-Sm-153, Ho-166, or RE-188 for bone metastasis treatment. Acta ortopedica brasileira, 27, 64-68, 2019.

[2]. Horn, E.M., Henn, J.S., Lemole Jr, G.M., Hott, J.S. \& Dickman, C.A. Thoracoscopic placement of dual-rod instrumentation in thoracic spinal trauma. Neurosurgery, 54, 1150-1154, 2004.

[3]. Harrington, K.D. The use of methylmethacrylate for vertebralbody replacement and anterior stabilization of pathological fracture-dislocations of the spine due to metastatic malignant disease. The Journal of bone and joint surgery, 63, 36-46, 1981.

[4]. Finlay, I.G., Mason, M.D. \& Shelley, M. Radioisotopes for the palliation of metastatic bone cancer: a systematic review. The lancet oncology, 6, 392-400, 2005.

[5]. Georgy, B. Metastatic spinal lesions: state-of-the-art treatment options and future trends. American Journal of Neuroradiology, 29, 1605-1611, 2008.

[6]. Emami, B., et al. Tolerance of normal tissue to therapeutic irradiation. International Journal of Radiation Oncology* Biology* Physics, 21, 109-122, 1991.

[7]. Ryu, S., et al. Image-guided and intensity modulated radiosurgery for patients with spinal metastasis. Cancer: Interdisciplinary International Journal of the American Cancer Society, 97, 20132018, 2003.

[8]. Ryu, S., et al. Partial volume tolerance of the spinal cord and complications of single dose radiosurgery. Cancer: Interdisciplinary International Journal of the American Cancer Society, 109, 628-636, 2007.

[9]. Ashamalla, H., et al. Phase I trial of vertebral intracavitary cement and samarium (VICS): novel technique for treatment of painful vertebral metastasis. International Journal of Radiation Oncology* Biology* Physics, 75, 836-842, 2009.

[10]. De la Calle, A., González-González, G., Fornés, C. \& MartínezCalderón, F. 153 SM-EDTMP (Samario) como tratamiento del dolor óseo de origen metastático. Revista de la Sociedad Española del Dolor, 13, 159-163, 2006.

[11]. Campos, T.P.R. \& Macedo, R.D.A. Compósito Ósseo Radioativo. Vol. PI 0605721-7 A2 (ed. Industrial, I.N.d.P.), Brasil, 2006.

[12]. Donanzam, B., Campos, T., Dalmázio, I. \& Valente, E. Synthesis and characterization of calcium phosphate loaded with Ho166 and Sm-153: a novel biomaterial for treatment of spine metastases. Journal of Materials Science: Materials in Medicine, 24, 2873-2880, 2013.

[13]. Hirsch, A.E., Medich, D.C., Rosenstein, B.S., Martel, C.B. \& Hirsch, J.A. Radioisotopes and vertebral augmentation: dosimetric analysis of a novel approach for the treatment of malignant compression fractures. Radiotherapy and Oncology, 87, 119-126, 2008.

[14]. Hirsch, A.E., Rosenstein, B.S., Medich, D.C., Martel, C.B. \& Hirsch, J.A. Polymethylmethacrylate and radioisotopes in vertebral augmentation: an explanation of underlying principles. Pain Physician, 12, 887-891, 2009.

[15]. Dale, R.G. The application of the linear-quadratic dose-effect equation to fractionated and protracted radiotherapy. The British journal of radiology, 58, 515-528, 1985. 
[16]. Goorley, J.T., et al. Initial MCNP6 release overview-MCNP6 version 1.0. Los Alamos National Lab.(LANL), Los Alamos, NM (United States), 2013.

[17]. Pelowitz, D.B., et al. MCNPX 2.7 E extensions. Los Alamos National Lab.(LANL), Los Alamos, NM (United States), 2011.

[18]. Lombardo, P.A. Development of the Realistic Anthropomorphic Flexible phantom for applications in dosimetry, 2018.

[19]. Trindade, B.M., Christóvão, M.T., de Fátima Maia Trindade, D., Falcão, P.L. \& de Campos, T.P.R. Comparative dosimetry of prostate brachytherapy with $\mathrm{I}-125$ and $\mathrm{Pd}-103$ seeds via SISCODES/MCNP. Radiologia Brasileira, 45, 2012.

[20]. Donanzam, B.A. Biocerâmicas com 166Ho e 153Sm: síntese, caracterização e avaliação dosimétrica em Radiovertebroplastia, 2012.

[21]. Meyerhof, E., et al. Radiation-induced toxicity after image-guided and intensity-modulated radiotherapy versus external beam radiotherapy for patients with spinal bone metastases (IRON-1): a study protocol for a randomized controlled pilot trial. Trials, 18 , 98, 2017.

[22]. LeGeros, R., Lin, S., Rohanizadeh, R., Mijares, D. \& LeGeros, J. Biphasic calcium phosphate bioceramics: preparation, properties and applications. Journal of materials science: Materials in Medicine, 14, 201-209, 2003.

[23]. Doube, M., et al. BoneJ: free and extensible bone image analysis in ImageJ. Bone, 47, 1076-1079, 2010.

[24]. Hartig, S.M. Basic image analysis and manipulation in ImageJ. Current protocols in molecular biology 102, 14.15. 11-14.15. 12, 2013.

[25]. Hehrlein, C. Is radioangioplasty next?, 2002.

[26]. Kang, H.J., et al. Hypofractionated intensity-modulated radiotherapy in patients with localized prostate cancer: a preliminary study. Radiation oncology journal, 34, 45, 2016.

[27]. Yamada, Y., et al. High-dose, single-fraction image-guided intensity-modulated radiotherapy for metastatic spinal lesions. International Journal of Radiation Oncology* Biology* Physics, 71, 484-490, 2008. 